\title{
Body part terms in Jahai
}

\author{
Niclas Burenhult
}

Max Planck Institute for Psycholinguistics, Postbus 310, 6500 AH Nijmegen, The Netherlands

\begin{abstract}
This article explores the lexicon of body part terms in Jahai, a Mon-Khmer language spoken by a group of hunter-gatherers in the Malay Peninsula. It provides an extensive inventory of body part terms and describes their structural and semantic properties. The Jahai body part lexicon pays attention to fine anatomical detail but lacks labels for major, 'higher-level' categories, like 'trunk', 'limb', 'arm' and 'leg'. In this lexicon it is therefore sometimes difficult to discern a clear partonomic hierarchy, a presumed universal of body part terminology.

(C) 2005 Elsevier Ltd. All rights reserved.
\end{abstract}

Keywords: Jahai; Mon-Khmer; Body part terms; Partonomy; Meronymy; Semantic fields; Semantic generality; Ambiguity

\section{Introduction}

In Jahai, a language spoken by a group of hunter-gatherers in the Malay Peninsula, the body serves as a productive, systematic and coherent metaphorical template with which the rest of the physical world is mapped, referred to and described. Landforms, houses, camps, trees, tools, fire and the universe as a whole are talked about in terms of 'bodies' exhibiting features like 'heads', 'eyes', 'noses', 'shoulders', 'bums' and 'feet'. An investigation of the Jahais' conceptualisation of 'thing' and 'space' thus requires an understanding

E-mail address: niclas.burenhult@mpi.nl 
of how they structure the human body. This study provides the first systematic account of body part terminology in Jahai.

\subsection{The Jahai and their language}

The Jahai are a group of about 1000 hunter-gatherers, traders and occasional swidden cultivators inhabiting the mountain rainforests of northern Peninsular Malaysia and adjacent parts of southern Thailand. They form the largest ethnic group of a cluster of hunter-gatherer populations in the Malay Peninsula referred to generically as Semang and belong to the scattered Southeast Asian pygmoid populations sometimes referred to with the racial label 'Negritos'. Their subsistence system is based on hunting, fishing and the collecting of wild tubers and vegetables. Traditionally, the Jahai live in mobile groups of 15-50 people, sheltering in windbreak huts and moving camp every one to two weeks. Nowadays many Jahai lead a settled or semi-settled life in regroupment programs established by the Malaysian government (van der Sluys, 1999, pp. 308310; Burenhult, 2002, pp. 1-3).

The language of the Jahai, referred to by the same name, is a member of the Northern Aslian subgroup of the Aslian languages, a branch of the Mon-Khmer language family. Characteristic features include a rich system of vowel phonemes, a complex system of word formation involving intricate processes of derivational affixation and reduplication, and rich pronominal and demonstrative distinctions. The Jahai language is heavily influenced by Malay, the Austronesian majority language of the peninsula, as reflected for example in a large number of loanwords (Burenhult, 2002).

\subsection{The present study}

This study describes the lexicon of body part terms in Jahai. It is concerned with the structural and semantic properties of such terms and lists the inventory of terms documented to date. It focuses on the nominal lexical labels of the parts of the body themselves. Other linguistic aspects of the body - such as body part-encoding verbs, metaphorical extension of body part terms to other physical domains, the significance of the body in the intrinsic frame of reference, and the use of measures based on parts of the body, all of which display interesting manifestations in Jahai-are not dealt with in this context. The study is to be regarded as a descriptive springboard for further exploration of body-related categorisation in Jahai.

The inventory of body part terms presented here has been collected during several fieldtrips between 1998 and 2003 to the semi-settled Jahai community of Kampung Sungai Banun, a resettlement village in Hulu Perak district in the state of Perak, Peninsular Malaysia. Data collection has been inspired and enriched by the elicitation guide developed by Enfield (this volume), which was employed in the field with three male Jahai consultants. The investigation has recently been supplemented and refined by the so-called 'Body colouring task' (van Staden and Majid, this volume), an elicitation tool in which consultants are asked to colour body parts on a drawing of the human body. This illuminating task was run with a subset of Jahai body part terms on eight male Jahai consultants. The present account is a synthesis of the results from these elicitation tasks. The 
following sections describe the structural properties of Jahai body part terms (Section 2), the inventory of terms (Section 3) and their semantic properties (Section 4). ${ }^{1}$

\section{Structural properties of Jahai body part terms}

\subsection{Morphological and phonological properties}

A Jahai body part term generally corresponds to a single lexeme, i.e. a synchronically unanalysable minimal free form. This holds true for $83 \%$ of the inventory of body part terms. Such terms are referred to here as simplex terms. The remaining terms represent derived, polylexemic nominal compounds. These latter forms invariably consist of a left-headed construction of two nominal lexemes. In such compounds, the head is typically represented by a metaphorical or other descriptive noun whereas the modifier consists of the body part term which specifies where on the body the feature is located, e.g. ?mpэy moh 'nostril', literally 'nose-hole'. Such terms are referred to here as complex terms.

However, some of the simplex body part terms display evident morphological complexity which is synchronically unanalysable. ${ }^{2}$ This manifests itself in fossilised reduplicative morphology involving processes of copying of consonants of the final syllable of the root. Some examples are listed below, with postulated obsolete roots marked with an asterisk (*). It is not known whether or not these unattested roots originally had the same meaning as the present-day complex forms.

\begin{tabular}{|c|c|c|}
\hline ltlet & 'groin' & ${ }^{*} l \varepsilon t$ \\
\hline$k r t l \tilde{t} t$ & 'kidney' & ${ }^{*} k r l \tilde{s} t$ \\
\hline$k m k \tilde{m} m$ & 'ankle' & ${ }^{*} k \tilde{m} m$ \\
\hline$\partial \eta$ & 'pharynx' & *prgay \\
\hline jwjaw & 'Achilles tendon' & *jaw \\
\hline
\end{tabular}

In nouns, such fossilised reduplicative morphology is restricted to two semantic classes, body part terms and animal names. ${ }^{3}$ Structurally identical processes of copying are still productive in the system of verbal derivation, where they signal imperfective aspect. In

\footnotetext{
${ }^{1}$ The orthography employed in this paper is phonemically based and largely conforms to IPA. It departs from standard IPA and from the orthography used in previous works by the author in that the voiced palatal stop is symbolised by $j$ and the palatal approximant by $y$. The typeface has been adapted for formatting by Geoffrey Benjamin, Singapore, and the author is grateful to him for supplying this version. The phonemic inventory of Jahai involves 20 consonant phonemes and 16 vowel phonemes, 9 oral vowels contrasting with a slightly smaller set of nasal counterparts (Burenhult, 2002, pp. 26-37).

2 The present use of the term simplex differs from the author's conventional use of the term (Burenhult, 2002, $\mathrm{p}$. 59 ), in which it is employed in the context morphologically simplex to define roots, which are unanalysable synchronically as well as diachronically. Here, simplex is defined as lexemically simplex.

${ }^{3}$ A connection between fossilised reduplicative morphology and names of body parts and animals has been noted in other Mon-Khmer languages as well, including Semelai, another Aslian language of Malaysia (Kruspe, 1999, pp. 156-157; Kruspe, 2004), and Minor Mlabri, a Kammuic language spoken in northeastern Thailand (Rischel, 1995, pp. 94-95).
} 
a fairly large number of verbs, however, this reduplicative morphology is frozen, so the lexeme form of the verb is represented by the morphologically complex but synchronically unanalysable form, much as in the case of the nominal forms described above. Most of these verbs denote bodily (especially oral) actions. Some examples are given below.

$\begin{array}{lll}\text { hchac } & \text { 'to whistle' } & { }^{*} h a c \\ j k j i k & \text { 'to breathe' } & { }^{*} j i k \\ \text { lkluk } & \text { 'to laugh' } & { }^{*} l u k \\ \text { hnjan } & \text { 'to stand' } & { }^{*} h j a n \\ \text { pysey } & \text { 'to say' } & { }^{*} \text { psey }\end{array}$

A couple of the morphologically complex forms denoting parts of the body may be derived from existing roots, but the semantic connection is not clear. These include $d k d u k$ 'chest' (cf. $d u k$ 'to pounce upon') and $s$ 'so? 'blood vessel' (cf. so? 'cubit'). Conversely, there is one example of reduplicative morphology being applied to a morphologically simplex body part term for noun-to-verb derivation: $k t$-kit 'to fart' from kit 'bum'. For details on morphological processes in Jahai and their derivational functions, see Burenhult, 2002, pp. 59-171.

As far as phonology is concerned, there may be a vague association between body part terms and a set of unusually occurring phonemically nasal vowels. Such nasal vowels are proportionately slightly more common among body part terms than among the rest of the lexicon (represented in about $16 \%$ of the inventory of body part terms as opposed to $10 \%$ in the lexicon as a whole, cf. Burenhult, 2002, pp. 26-28). Again, a similar association is evident in the class of animal names.

\subsection{Syntactic properties}

Possessive constructions in Jahai involve a nominal head denoting the possessed entity followed by a nominal or pronominal possessor. The possessor slot of the NP is always to the immediate right of the head. Possessive constructions do not involve additional morphological marking and are therefore structurally similar to compounds (Burenhult, 2002, pp. 98-100, 190-191). The expression of possession of parts of the body adheres to this structure, as illustrated by examples (1) and (2):
(1) ?ntey
tmkal
ear man
'the man's ear'
$\begin{array}{ll}\text { (2) } b l i ? & ? o^{?} \\ \text { upper.leg } & 3 \mathrm{~S}\end{array}$
'his/her/its upper leg'

Like all Jahai nouns, those denoting parts of the body do not syntactically or morphologically require an overt possessor, and there is no formal distinction of alienable vs. inalienable possession. However, an overt possessor is usually present in NPs headed by 
body part nouns as well as nouns of some other semantic classes, e.g. kinship and landscape terms (Burenhult, 2002, pp. 192-193).

Jahai lacks gender distinction in nouns, and nouns are not marked for number. A peripheral form of number-marking involves a 'collective plural' largely restricted to human nouns (Burenhult, 2002, pp. 100-101). However, when quantified, nouns are usually individualised by means of a specific affix labelled 'UNIT' (Burenhult, 2002, pp. 102-104). This also applies to nouns denoting parts of the body, as shown in example (3).

$n \varepsilon y \quad n n-c a n$
one UNIT-foot
'one foot'

\section{The inventory of Jahai body part terms}

This section presents the total inventory of Jahai body part terms documented to date by the author (150 items). It is divided into subcategories covering features of the face (Section 3.1), external parts (Section 3.2), internal parts (Section 3.3), other parts (Section 3.4) and animal anatomy (Section 3.5). This division is sometimes problematic, as terms occasionally belong in more than one subcategory. Such semantically general or ambiguous terms are dealt with in all relevant subsections. It is sometimes also difficult to decide in which subcategory a particular term belongs, for example when it has properties that clearly define it as belonging to one subcategory but at the same time connections to items in another subcategory, e.g. through derivation. Such terms have been assigned subjectively to that subcategory in which they have their most apparent connections. The subcategorisations are therefore to be taken as only a rough guideline.

The documented terms include mostly indigenous Jahai words but also occasional loans from Malay. In some cases a part of the body may be referred to with either a Jahai term or a borrowed Malay term; such parallel Malay terms are included if they are of frequent use and/or presumed to be a feature of a particular register.

In each of the following subsections the Jahai body part terms are listed in a table (see Tables 1-5). The items there are accompanied by an approximate English translation (usually the colloquial English equivalent but, if necessary, a more technical term) and also additional information with regard to meaning (morpheme-by-morpheme translation, specifying medical terminology, ambiguity, etc.), origin and markedness of the term. $^{4}$

\subsection{Features of the face}

The 'face' is defined here as the oval-shaped area on the front of the head, including forehead, eyebrows and chin, but not including head-hair, ears or neck. There is no Jahai

\footnotetext{
${ }^{4}$ Translations of Malay terms are based on Coope (1993). The use of medical terminology draws on Feneis (1974).
} 
Table 1

Jahai terms denoting features of the face

\begin{tabular}{|c|c|c|}
\hline Jahai term & Translation & Other information \\
\hline \multicolumn{3}{|l|}{ Simplex } \\
\hline$p t \dot{t}^{?}$ & 'forehead' & \\
\hline$w \tilde{\varepsilon} s$ & 'frontal tuber' & refers to the prominent ridges on either side of the forehead \\
\hline cuntĩy & 'temple' & \\
\hline cycĩg & 'spectacles' & regio orbitalis \\
\hline mit & 'eye’ & \\
\hline knhir & 'root of the nose' & refers to the wrinkles between the eyebrows \\
\hline$m \supset h$ & 'nose' & \\
\hline nus & 'upper lip' & incl. all of the fleshy part between mouth and nose \\
\hline miscy & 'mustache' & from Malay misai 'mustache' \\
\hline tnit & 'lower lip' & incl. all of the fleshy part between mouth and chin \\
\hline$h \tilde{\varepsilon} n$ & 'tooth' & \\
\hline$m \eta k a ?$ & 'molar tooth' & \\
\hline lntek & 'tongue' & \\
\hline kapo? & 'cheek' & \\
\hline jey & 'whiskers' & \\
\hline yayka? & 'mandible' & \\
\hline jayut & 'beard' & from Malay janggut 'beard' \\
\hline \multicolumn{3}{|l|}{ Complex } \\
\hline cawĩy mit & 'eyebrow’ & independent meaning of $c a w \tilde{\imath} \eta$ not known \\
\hline smpsy mit & 'eyelid' & independent meaning of smpsy not known \\
\hline katey moh & 'bridge of the nose' & independent meaning of katey not known \\
\hline ?трэу тэһ & 'nostril' & lit. 'nose-hole' \\
\hline carək nus & 'philtrum' & lit. 'upper lip streambed'; carək from Malay caruk 'runnel' \\
\hline$k t \dot{t}^{\prime}$ tnit & 'lower lip' & lit. 'lower lip skin' (the membranous part of the lower \\
\hline & & lip lining the rima oris) \\
\hline
\end{tabular}

term for 'face'; if asked about a corresponding term consultants invariably suggest mit 'eye' as the most suitable equivalent but maintain that there is no word for what the Malay refer to as muka 'face'. Another notable feature of the facial terminology is the lack of a term specifically referring to the mouth (i.e. the oral region as a whole or the cavity as such); the closest equivalent is $h \tilde{\varepsilon} n$ 'tooth', 'teeth'. Furthermore, there is a term referring to the biorbital region, i.e. a spectacle-shaped area around both eyes: çcĩ . Other features

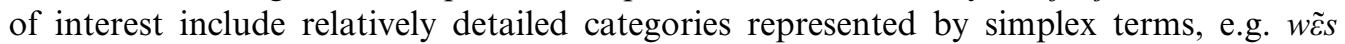
'frontal tuber', nus 'upper lip' and $m \eta k a$ ' 'molar tooth'. Complex terms describe details related to the eyes, nose and lips. The meanings of these are not always fully transparent, although at least one identifiable metaphor (a landscape term) is in evidence: carək nus 'philtrum', literally 'upper lip streambed' (Fig. 1).

Terms referring to features of the face (23 items) are listed in Table 1.

\subsection{External parts}

This subsection describes terms for external parts of the body other than features of the face. The documented inventory of such terms is large ( 76 items, see Table 2 ) so only the more general patterns will be described here. 
Table 2

Jahai terms denoting external parts of the body

\begin{tabular}{|c|c|c|}
\hline Jahai term & Translation & Other information \\
\hline \multicolumn{3}{|l|}{ Simplex } \\
\hline ley & 'body' & \\
\hline saro? & 'corpse' & \\
\hline$k t \dot{t} ?$ & 'skin’ & \\
\hline sok & 'hair' & \\
\hline kuy & 'head' & \\
\hline$l k x$ & 'fontanel' & marked term? \\
\hline lplĩp & 'fontanel' & unmarked term? \\
\hline ?ntey & 'ear’ & \\
\hline ?yut & 'throat' & \\
\hline prygə⿱ & 'pharynx' & \\
\hline tykok & 'nape of the neck' & \\
\hline tayin & 'shoulder' & regio colli lateralis \\
\hline$k r \jmath^{?}$ & 'back' & \\
\hline dada? & 'chest' & unmarked term; from Malay dada 'chest' \\
\hline$d k d u k$ & 'chest' & marked term \\
\hline$? \tilde{\varepsilon} m$ & 'breast' & \\
\hline cluno? & 'solar plexus' & regio epigastrica \\
\hline paw & 'side' & \\
\hline$? \varepsilon c$ & 'belly' & $\begin{array}{l}\text { refers also to the internal part 'bowels' and the bodily } \\
\text { product 'shit' }\end{array}$ \\
\hline$g \varepsilon l$ & 'waist' & \\
\hline$d u t$ & 'navel' & \\
\hline kit & 'bum' & \\
\hline tntkit $\sim$ kntkit & 'anus' & $\begin{array}{l}\text { marked, possibly derived term; probably a location } \\
\text { nominalisation meaning 'place of farting' }\end{array}$ \\
\hline hawor $\sim$ hawir & 'buttock' & \\
\hline ltlet & 'groin' & \\
\hline$d s t$ & 'vulva' & unmarked term \\
\hline$k m \varepsilon t$ & 'vulva' & $\begin{array}{l}\text { rude marked term; homonymous with the name for } \\
\text { a type of frog }\end{array}$ \\
\hline$l a^{?}$ & 'penis' & \\
\hline$? n t \varepsilon p$ & 'scrotum' & \\
\hline klapəh & 'shoulder' & regio deltoidea \\
\hline$l d a^{?}$ & 'armpit' & \\
\hline bliy & 'upper arm' & \\
\hline kaỹ̃y & 'elbow’ & \\
\hline prber & 'lower arm' & \\
\hline cyas & 'hand' & \\
\hline kaỹ ? & 'finger', 'little finger' & \\
\hline jari? & 'finger' & from Malay jari 'digit' \\
\hline$k l k s^{?}$ & 'nail' & \\
\hline kat $\tilde{\eta}$ & 'nail' & \\
\hline kukuh & 'nail' & from Malay $k u k u$ 'nail' \\
\hline cnros & 'nail' & $\begin{array}{l}\text { possibly a loan of Temiar cenross 'claw', 'nail'; } \\
\text { claimed by individual consultants to refer to the bones } \\
\text { of the hand/foot and digits }\end{array}$ \\
\hline tem & 'right' & associated with the right hand, arm or body half \\
\hline$w \tilde{\imath} ?$ & 'left' & associated with the left hand, arm or body half \\
\hline
\end{tabular}


Table 2 (continued)

\begin{tabular}{|c|c|c|}
\hline Jahai term & Translation & Other information \\
\hline$b l i ?$ & 'upper leg' & \\
\hline kaltoy & 'knee' & \\
\hline layst & 'hollow of the knee' & \\
\hline gor & 'lower leg' & \\
\hline can & 'foot' & \\
\hline kmkãm & 'ankle' & malleolus \\
\hline jwjaw & 'Achilles tendon' & \\
\hline$d l d u l \sim d l d \tilde{\boldsymbol{t}} l$ & 'heel' & \\
\hline crkip (can) & 'heel' & \\
\hline krtwĩt & 'wrinkles' & \\
\hline krnten & 'wrinkles' & \\
\hline hrnpen & 'goose-bumps' & \\
\hline$k s i t$ & 'birthmark' & \\
\hline cmac & 'boil', 'wound' & \\
\hline bisol & 'boil', 'wound' & from Malay bisul 'boil' \\
\hline$g a s \sim g \tilde{\varepsilon} s$ & 'skin disease' & \\
\hline$c \partial c \sim c \partial c$ & 'scar' & marked term? \\
\hline parut & 'scar' & unmarked term?; from Malay parut 'scar' \\
\hline \multicolumn{3}{|l|}{ Complex } \\
\hline kmo? ? yut & 'Adam's apple' & lit. 'throat-fruit' \\
\hline dapor $7 \tilde{\varepsilon} m$ & 'nipple' & $\begin{array}{l}\text { lit. 'breast-hob'; loan/calque of Malay dapur-dapur susu } \\
\text { 'outer portion of breast', dapur 'kitchen', 'oven' }\end{array}$ \\
\hline ?mpэy kit & 'anus' & lit. 'bum-hole' \\
\hline$k t t^{\prime} l a^{?}$ & 'foreskin' & lit. 'penis-skin' \\
\hline tupih la? & 'foreskin' & lit. 'penis-hat'; tupih from Malay topi 'hat' \\
\hline krĩl $($ cyas $)$ & 'wrist' & lit. '(hand-)joint' \\
\hline dada? cyas & 'palm of hand' & lit. 'hand-chest'; marked term \\
\hline tapar cyas & 'palm of hand' & $\begin{array}{l}\text { from Malay tapak 'palm of hand', 'sole of foot'; } \\
\text { unmarked term }\end{array}$ \\
\hline kro? cyas & 'back of hand' & lit. 'hand-back' \\
\hline tabo?(cyas) & 'thumb' & lit. 'big digit (of hand)' \\
\hline$k r i \tilde{l}(\mathrm{can})$ & 'ankle joint' & lit. '(foot-)joint' \\
\hline dada? can & 'sole of foot' & lit. 'foot-chest'; marked term \\
\hline tapar can & 'sole of foot' & $\begin{array}{l}\text { from Malay tapak 'palm of hand', 'sole of foot'; } \\
\text { unmarked term }\end{array}$ \\
\hline$k r \jmath^{?}$ can & 'back of foot' & lit. 'foot-back' \\
\hline tabo? $(c a n)$ & 'big toe' & lit. 'big digit (of foot)' \\
\hline
\end{tabular}

There is a general term for body, ley, which refers to the whole organism, but otherwise coarse, high-level categorisation is largely absent. For example, there are no terms that correspond to upper or lower part of the body, trunk, torso, limb or the like. Also, as we shall see further below, there are no terms corresponding to arm and leg. As far as head is concerned, the Jahai equivalent kuy appears to denote only that part of the head which is covered by the head-hair. In the colouring task, for example, Jahai consultants uniformly exclude the face (usually also the forehead) when indicating kuy. This is surprising especially since there is no corresponding term for face (see Section 3.1); facial features thus seem to be part of an unnamed entity which, in turn, is not part of the head. 
Table 3

Jahai terms denoting internal parts of the body

\begin{tabular}{|c|c|c|}
\hline Jahai term & Translation & Other information \\
\hline \multicolumn{3}{|l|}{ Simplex } \\
\hline smutlõt & 'brain’ & marked term? \\
\hline lkem & ‘brain’ & unmarked term? \\
\hline sop & 'lung' & \\
\hline klayis & 'heart' & \\
\hline darah & 'blood' & unmarked term; from Malay darah 'blood' \\
\hline 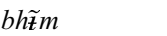 & 'blood' & marked term used only in mythical contexts? \\
\hline ros & 'liver' & \\
\hline krtlist & 'kidney' & \\
\hline kmit & 'gall bladder' & homonymous with 'knee-cap' \\
\hline kпэт & 'urinary bladder’ & refers also to the bodily product 'urine' \\
\hline$? \varepsilon c$ & 'bowels' & $\begin{array}{l}\text { incl. ventriculus gaster and ilia; refers also to } \\
\text { the external part 'belly' and the bodily product 'shit' }\end{array}$ \\
\hline $\operatorname{lm} a^{?}$ & 'bowels' & possibly from Malay lemak 'fat', 'grease' \\
\hline$s^{2} s o^{\prime}$ & 'blood vessel' & possibly also refers to 'tendon' \\
\hline$s \varepsilon c$ & 'muscle', 'flesh', 'meat' & \\
\hline l'as & 'fat', 'fatty tissue' & \\
\hline gmu? & 'fat' & from Malay gemuk 'fat' \\
\hline j’e & 'bone', 'skeleton' & \\
\hline labəy & 'skull' & \\
\hline slajka? & 'collar-bone' & from Malay selangka 'collar-bone' \\
\hline taps̃h & 'pelvis' & \\
\hline$w \tilde{x} c$ & 'caudal vertebra' & \\
\hline cntel & 'seat-bone' & tuber of ischium \\
\hline kmit & 'knee-cap' & homonymous with 'gall bladder' \\
\hline Complex & & \\
\hline kmo? ?ntcp & 'testicle' & lit. 'scrotum-fruit' \\
\hline$k b \dot{t}>$ ?ntep & & \\
\hline
\end{tabular}

Table 4

Jahai terms denoting bodily excretions, shadow and soul

\begin{tabular}{|c|c|c|}
\hline Jahai term & Translation & Other information \\
\hline \multicolumn{3}{|l|}{ Simplex } \\
\hline lhey & 'phlegm', 'saliva', 'snot' & \\
\hline mam & 'mother's milk' & \\
\hline bykit & 'sweat' & possibly derived from bkit 'to be hot' \\
\hline knom & 'urine' & refers also to the internal part 'bladder' \\
\hline$? \varepsilon c$ & 'shit' & $\begin{array}{l}\text { refers also to the internal part 'bowels' and } \\
\text { the external part 'belly' }\end{array}$ \\
\hline sdiy & 'vomit' & \\
\hline layxy & 'shadow' & \\
\hline jrey & 'soul' & \\
\hline rway & 'life soul' & \\
\hline \multicolumn{3}{|l|}{ Complex } \\
\hline tom $k t t^{\prime}$ & 'sweat' & lit. 'skin-water' \\
\hline tom mit & 'tear' & lit. 'eye-water' \\
\hline
\end{tabular}


Table 5

Jahai terms denoting animal anatomy

\begin{tabular}{|c|c|c|}
\hline Jahai term & Translation & Other information \\
\hline \multicolumn{3}{|l|}{ Simplex } \\
\hline hatĩ? & 'tail' & \\
\hline syuy & 'fang' & from Malay siung 'canine teeth' \\
\hline gadiy & 'tusk' & of boar and elephant; from Malay gading 'tusk', 'ivory' \\
\hline tano? & 'horn' & possibly also meaning 'fin'; from Malay tanduk 'horn' \\
\hline tanus & 'boar's snout' & \\
\hline somu? & 'tapir's snout' & \\
\hline blaley & 'elephant's trunk' & from Malay belalai 'trunk' \\
\hline plysay & 'palp' & of fish; possibly derived from Malay misai 'mustache' \\
\hline klek & 'quill' & of porcupine \\
\hline harim & 'quill' & of porcupine's tail \\
\hline sayap & 'wing' & from Malay sayap 'wing' \\
\hline cnep & 'tail feathers' & \\
\hline спэу & 'beak', 'bill', 'nib' & \\
\hline krkok & 'casque' & the characteristic adornment on the bill of most species of hornbill \\
\hline ktit & 'egg' & \\
\hline maks? & 'egg' & \\
\hline
\end{tabular}

As for the trunk, there is a term referring to the dorsal region: $k r \jmath^{?}$ 'back'. This is usually described as covering the back from the nape of the neck to the caudal vertebra. However, one consultant also includes the back of the head. The anterior region encompasses categories like $d a d a$ ' (or $d k d u k$ ) 'chest', ? $\tilde{\varepsilon} m$ 'breast', ' $\varepsilon c$ 'belly' and cluno? 'solar plexus'. The terms $k r{ }^{\prime}$ ' and $d a d a$ ' are also used with more general, extended meanings of 'back' and 'front' to signify body-external posterior and anterior zones. The term $g_{\varepsilon} l$ 'waist' refers to a narrow circumferential girdle-like region presumably associated with the tying and wearing of

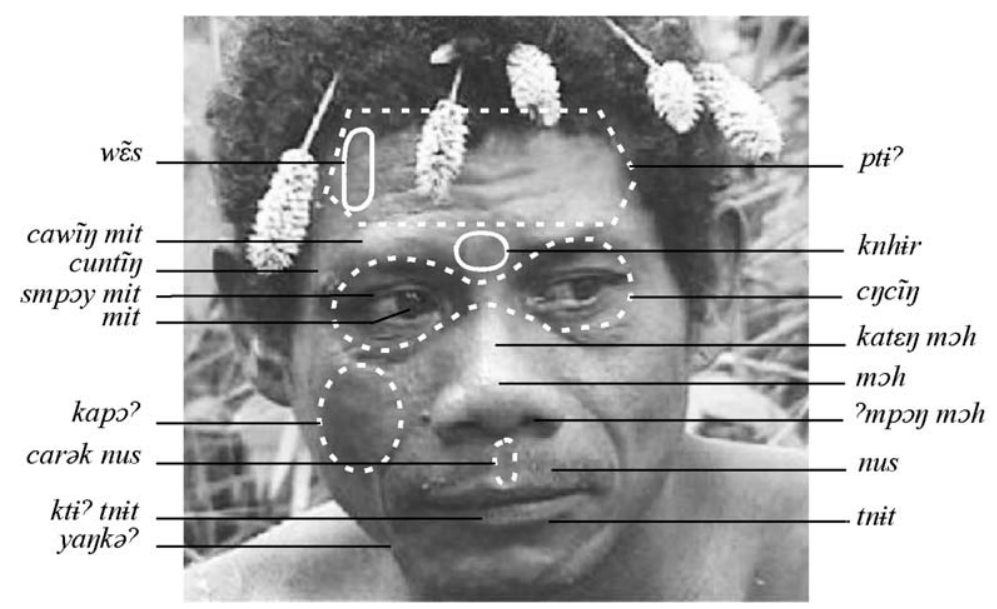

Fig. 1. Features of the face. 


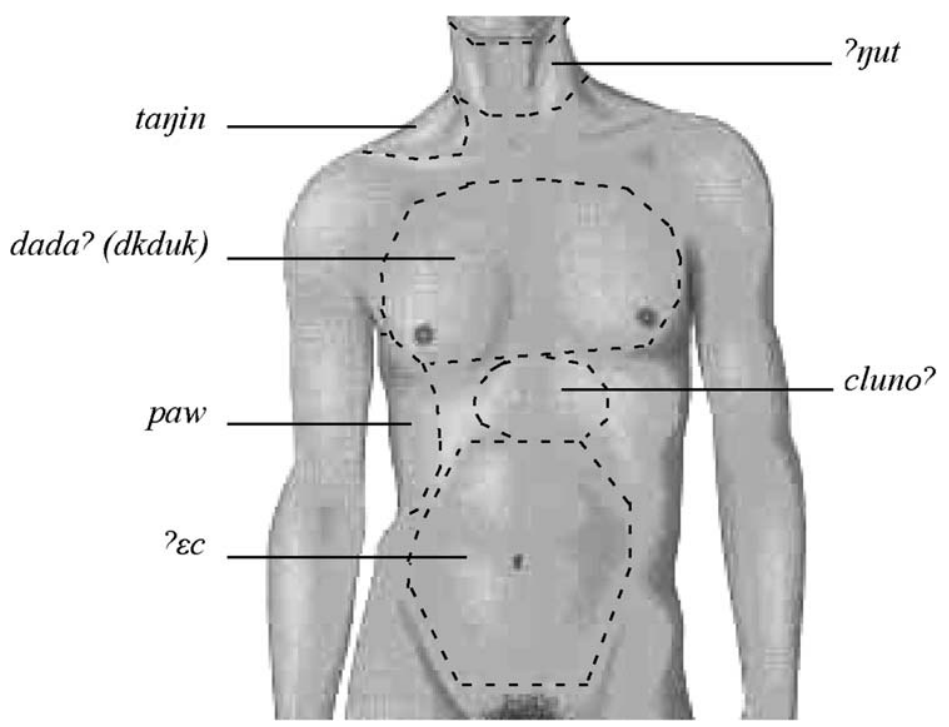

Fig. 2. Major segments of the anterior part of the trunk and their associated body part terms.

clothes (notably the loin-cloth) and carrying of tools. Laterally, the term paw refers to the side of the trunk, from the armpit to the hip. The soft upper part of the shoulder (regio colli lateralis) is referred to as tayin (Fig. 2).

The limbs are segmented into several parts signified by specific (usually simplex) terms. There are no general terms that cover limb, arm or leg. The upper extremities are segmented into the deltoid part of the shoulder (klapah), the upper arm (blin), the elbow (kaỹ̃y), the lower arm (prbsr), the wrist (krĩl) and the hand (cyas). Analogously, the lower extremities are segmented into upper leg (bli $)$, knee (kaltoy), lower leg (gor), ankle joint $(k r i ̂ l)$ and foot (can). ${ }^{5}$ These main extremity categories are referentially discrete in that they do not seem to overlap in extension (see Section 4.1 and Fig. 3). There are also simplex terms for details like armpit, heel, Achilles tendon, ankle and the hollow of the knee.

The labelling of the digits and nails presents a bewildering case of idiolectal variation. The thumb and the big toe are consistently referred to as tabo?. The remaining digits are sometimes claimed not to have any label, simply being covered by the term for hand and foot respectively. However, one consultant gives the term kayĩ for all digits excluding thumb and big toe; another consultant claims kay $\tilde{\imath}^{\text {? }}$ only refers to the little finger. However, the Malay loan jari? may be used to refer to all digits. Nails on both hands and feet may be referred to as $k l k \jmath^{\text {? }}$, kat $\tilde{y}$ or kukuh (from Malay kuku 'nail'). The difference

\footnotetext{
5 Wilkins (1981, pp. 203-204) mentions a similar lack of labels corresponding to 'arm' and 'leg' in many Australian languages. This is also what some dictionaries suggest, see e.g. Osborne (1974) for Tiwi, Dixon (1991) for Yidiny, and Austin (1992) for Thalanyji. Also, Nicole Kruspe (personal communication) reports of segmentation of the limbs identical to that of Jahai in Semelai and Che Wong, two Aslian relatives in Malaysia.
} 


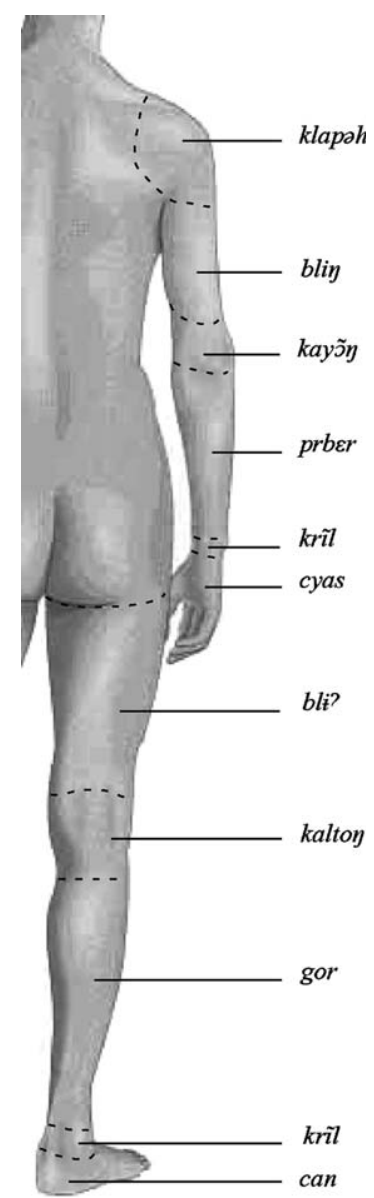

Fig. 3. Major segments of the upper and lower extremities and their associated body part terms. Note the parallelism in segmentation between the upper and lower extremity and the lack of labels for 'higher-level' categories like limb, arm and leg.

between the two indigenous terms is not known. Also, the term $\operatorname{cnros}^{6}$ is usually explained as 'nail', but according to one consultant it refers to the bones of the metacarpus and fingers as well as the metatarsus and toes; another consultant claims cnros only refers to the distal phalanges. ${ }^{7}$ The palm/sole and back of the hand and foot are referred to with complex terms involving for example a metaphor meaning chest or back.

The words for right (tem) and left ( $w \tilde{\imath}$ ?) have clear association with the respective lateral parts of the body, usually the upper extremities, but judgments vary as to what they actually denote. They are probably best interpreted as signifying more general lateral bodybased zones rather than true parts of the body.

\footnotetext{
${ }^{6}$ This is possibly a loan from the neighboring Aslian language Temiar; cf. (Benjamin, 1976, p. 104).

${ }^{7}$ Gaby (this volume) reports of similar idiolectal variation in extensional range of digit terms in Kuuk Thaayorre.
} 
Hair is referred to generically as sok. Further specification is achieved by combining this term with the relevant body part term, e.g. sok kuy 'head-hair' and sok dada? 'chest-hair'. This pattern of derivation appears to be productive; examples have not been included in the table below. The same pattern applies to ktï' 'skin'.

Most terms for external parts are simplex, complex terms being restricted to details of the throat, breasts, bum, genitals, hands and feet. These derived compounds typically involve a descriptive or metaphorical noun, e.g. 'mpэy 'hole' and kmo? 'fruit', followed by the modifying body part term.

\subsection{Internal parts}

Internal parts of the body here include internal organs, tissue, skeletal parts and fluids (excluding excretions, see Section 3.4). The documented number of items is 24 . These are listed in Table 3. They probably represent only part of the total inventory of terms denoting internal parts of the body; further elicitation is likely to reveal more detail.

Some internal parts (including the brain, blood, bowels and fat) are associated with more than one term, an indigenous term typically co-existing with a synonymous Malay loan. In one such case (the indigenous term bhĩm 'blood' and the Malay loan darah 'blood') the Malay term has replaced the indigenous one almost completely, the latter being restricted to certain registers, including myth-telling. It is possible that such synonymy is indicative of the employment of Malay forms as avoidance terms.

The skeleton and its bones are referred to generically as $j^{\prime}$ ey 'bone'. Further specification of skeletal parts is achieved by combining this term with the relevant body part term, e.g. j'ey blit' 'thigh-bone' (literally 'upper leg bone') and $j^{\prime} e \eta$ dada' 'rib-cage' (literally 'chest-bone'). This pattern appears to be productive; examples have not been included in the table below. However, there is a handful of simplex terms signifying individual parts of the skeleton, including words for skull, collar-bone, pelvis, caudal vertebra, seat-bone and knee-cap. Incidentally, it is difficult to determine whether some of these simplex terms denote only the skeletal part as such or if they also cover the visible external shape in the skin and thus whether they are to be treated as internal parts or not.

The term kmit presents a puzzling case of ambiguity, as it refers to both gall-bladder and knee-cap. Semantically unrelated homonyms are rare in Jahai, so it is tempting to explain it in terms of a vague relation of polysemy based on shape and size, but such a connection cannot be substantiated at present.

\subsection{Other parts}

This category includes terms that do not fit into any of the previous three categories, including those denoting bodily excretions and a couple of forms denoting the soul, notably rway 'life-soul'. ${ }^{8}$ There are ten such items, listed in Table 4.

\footnotetext{
${ }^{8}$ According to van der Sluys (1996, p. 6), the rway is considered by the Jahai to be a soul-substance centered in and around the heart (the center of emotions and thought) and is visualised as "a fine, invisible vapor, similar to the scent that emanates from a flower's nectar or from the fragrant sap of crushed leaves".
} 
The terms knom and ${ }^{\varepsilon} c$ are semantically general in that they cover both body parts and the bodily excretions associated with those parts: 'urinary bladder'/'urine' and 'belly'/ 'bowels'/'shit' respectively. Furthermore, they represent unusual examples of roots which have both nominal and verbal meaning, since they also denote 'to urinate' and 'to shit' (see Burenhult, 2002, p. 96). ${ }^{9}$

\subsection{Animal anatomy}

The terms used for parts of the human body apply to animal bodies as well. For example, terms associated with the upper and lower limbs of humans apply in animals to the front and back legs respectively; the different terms for nail also mean 'claw'; the term denoting hair also includes 'feathers', 'plumage', 'down'; the term for skin covers also the scales of fish; and so on. Terms are therefore sometimes semantically more general than their English glosses imply. So far, no documented body part term can be shown to be uniquely human. Inversely, however, there is a set of terms denoting anatomical features of some animals which do not apply to human anatomy. Sixteen such terms have been documented and are listed in Table 5. This is obviously not an exhaustive list; further probing is likely to unveil a rich vocabulary of specifically animal parts.

\section{Semantic properties}

This section discusses Jahai body part terms in the context of two issues of semantic relations: semantic generality and ambiguity (Section 4.1) and partonomy (Section 4.2).

\subsection{Semantic generality and ambiguity}

As will be noted in Section 4.2, Jahai body part terms are characterised by referential discreteness and a scarcity of higher-level terms that subsume other terms. Accordingly, there is little evidence that a term referring to one part can be semantically generalised and extended (e.g. on the basis of structural similarity or contiguity) to include parts covered by other terms (cf. the discussion of Andersen, 1978, pp. 353-359 on body part polysemy). However, two terms associated with the limbs deserve special attention in this respect. In some specific contexts, the terms referring to the uppermost portion of the upper and lower limbs, klapzh 'shoulder' and $b l i{ }^{\text {' }}$ 'upper leg' respectively, appear to be able to dominate lower segments of their respective 'host' limb. For example, when cutting up an animal and distributing its pieces, the Jahai will refer to upper limbs/front legs as $k l a p a h$ and lower limbs/back legs as bli' ${ }^{\prime}$. In what may reflect a related notion, two consultants doing the colouring task preferred to colour the whole lower limb on one of the two occasions they were asked to indicate $b l i{ }^{\prime}$ ' 'upper leg', and one consultant colored the

\footnotetext{
${ }^{9}$ Blake (1979, p.192) mentions similar unusual noun-verb overlap for 'piss'/'to piss' and 'shit'/'to shit' in PittaPitta, a Pama-Nyungan language of southwest Queensland.
} 
whole upper limb on one of the two occasions he was asked to indicate klapah 'shoulder'. Also, in metaphorical extension of parts of the body to other domains (like landscape features) - which typically involves a limited subset of the body part terms - upper and lower limbs are frequently only represented by klapah and bli'? . Upon questioning, however, consultants will invariably and firmly oppose the suggestion that the terms cover anything more than the deltoid part of the shoulder and the upper leg respectively. This is also the dominant pattern coming out of the colouring task. It will therefore be concluded here that these wider uses of klapah and bli cannot at present be interpreted as cases of semantic extension and generalisation. Rather, the terms will be thought of as being employed in these contexts by virtue of representing the first and anatomically most salient feature beyond the 'cut', the other features simply happening to be attached to it.

Another interesting case concerns those terms whose meanings range across both anatomy, bodily excretions and the acts of excreting, thus extending beyond the body itself. The term ? $\varepsilon c$ has a particularly wide-ranging set of meanings, including the external body part 'belly', the internal body part 'bowels', the bodily excretion 'shit' and the act 'to shit'. Although the cross-categorial nature of these terms may suggest a relationship of ambiguity (or polysemy), it is clear that they form a closely connected continuum of meanings in which adjacent members are difficult to tease apart. Thus, distinguishing external 'belly' from internal 'bowels' is difficult (compare English stomach), as is distinguishing 'bowels' from their excretory contents 'shit'. The categorial leap to the verbal word class represented by 'to shit' is easy to distinguish on structural grounds and may seem less problematic; recall, however, that such homonymous nominal and verbal lexemes are rare in Jahai. The term knom represents a urinary parallel case. ${ }^{10}$

\subsection{Partonomy}

The body part domain is usually described as universally hierarchical in nature, frequently being put forward as the most evident example of the semantic relation of partonomy, i.e. 'part of' relationship, which is different in nature from e.g. the relation of taxonomy, expressing 'kind of' relationship (Brown, 1976, pp. 400-401; Andersen, 1978, pp. 347-348). Furthermore, analyses of the lexical structure of the body part domain suggest universal constraints on such body part partonomies. For example, according to the so-called 'depth principle', human anatomical partonomies rarely exceed five hierarchical levels of depth and never exceed six hierarchical levels (Brown, 1976, p. 404; see also Andersen, 1978, pp. 348-351).

In describing partonomic relationships between Jahai body part terms we face some interesting difficulties. Firstly, the concept of a 'part of' relationship may not be self-evident in Jahai. There is for example no documented term corresponding to 'part', 'piece', 'segment' or the like, and consultants never explain in other ways a feature of the body in terms of being part of another feature. ${ }^{11}$ Instead, the main linguistic (and

\footnotetext{
${ }^{10}$ Source/product metonymy in the context of excreta is described for Kuuk Thaayorre by Gaby (this volume).

11 Brown (1976, note 7) quotes statements expressing similar situations in other languages, including Machiguenga and Hopi. Gaby (this volume) and Meira (this volume) describe the same circumstances in Kuuk Thaayorre and Tiriyó respectively.
} 
metalinguistic) devices available for expressing (and eliciting) partonomic-like relationship concepts are possessive constructions and derived compounds (which are difficult to tease apart in Jahai, structurally as well as semantically, and which incidentally do not necessarily entail a part-whole relationship). As we have seen, the latter are employed as fixed, derived terms to denote some details of parts of the body, e.g. 'back of hand'. Furthermore, some terms denoting distributed rather than well-defined parts are particularly productive in being able to be modified by other body part terms, including hair, skin, flesh and bone, e.g. 'skin of lower leg'. It is unclear whether these less fixed derivations are to be regarded as general compounds or more specifically possession-signalling constructions.

However, with the possible exception of such derived forms, features' "possession" of other features is not very much in evidence. Of course, any body part term can (and typically does, cf. Section 2.2) represent the possessed item in a construction where the possessor is represented by a person. But, as far as can be determined, constructions with simplex body part terms standing in a possessive relation to each other do not occur. Incidentally, such constructions would be entirely redundant. Although not rejected off-hand, such possessive constructions come across as rather artificial to consultants. Similar problems apply to possible possessive relations expressed with predicative constructions, like ' $x$ has a $y^{\prime}$.

Secondly, again with the possible exception of the complex terms, the extensional range of body part terms, as revealed by interviewing, generally gives the impression of being characterised by referential discreteness. Consultants give precise infor- mation as to where a certain part ends and the next one begins and their indications suggest there is little overlap in the segmentation of named parts: descriptions of two simplex terms which are partly co-referential typically do not occur. An obvious exception here is ley 'body', which covers all of the other parts together. In the colouring task, consultants' indications appear similarly discrete, although there are occasional examples where the referent of a term is depicted as extending to cover parts associated with other terms (cf. Section 4.1). Upon further questioning about these exceptions, consultants will usually consider such extensions incorrect. Thus, as far as simplex terms are concerned, the overall impression is a preference for an almost atomistic one-to-one relationship between part and term.

This appears to go hand in hand with the lack of labels for 'higher-level' categories like upper body, trunk and torso, and it becomes particularly evident in the segmentation of the limbs and the absence of terms corresponding to arm and leg. Recall that upper and lower limbs are segmented into six and five distinct parts respectively, each with its own simplex term label. It may also be connected to the apparent exclusion of the facial area from the head, and the lack of a label for face as such, as well as the lack of a label corresponding to mouth. In this context, note the existence of simplex terms denoting detailed features, e.g. of the face. So, apart from body itself, there are few labelled 'high-level' candidates which can be described as 'subordinating' or 'possessing' other features denoted by simplex terms. Or, to give an example, nus 'upper lip', although a part of the body, cannot be expressed as being part of (or possessed by) the head, the face or even the mouth. If anything, the Jahai system of simplex body part terms appears to be characterised by what we may call 'hierarchy avoidance'. The unclear terminology associated with digits may represent an exception as it can sometimes be interpreted as reflecting segmentation of the hands and feet. 
The complex terms also present little evidence for partonomic relationships. As noted in Section 2, these are compounds of two nominal lexemes, where the head of the construction is a metaphorical or other descriptive noun and the modifier is a body part term which specifies where on the body the feature is located, e.g. 'mpэy moh 'nostril' (literally 'nosehole'). In the absence of a specific linguistic device for expressing the 'part of' relationship, it is difficult to determine whether these possessive-like compounds denote such a relationship. They may just as well express something more general, such as a feature's spatial contiguity with or proximity to another feature (cf. Andersen, 1978, pp. 357-359). In other words, the presence of a modifying term denoting a part of the body does not necessarily entail that the feature is a sub-part of that part, e.g. that the eyebrow is part of the eye. In Jahai this may be particularly evident in the terms for wrist and ankle-joint, where a single term $k r i \tilde{l}$ is optionally made specific by means of a modifier denoting hand or foot. However, the krĩl as such is never described or indicated as part of the hand or foot; the association seems to be entirely based on contiguity. The same may hold for the similarly nonspecific klks? (or kat ̃̃y) 'nail' and tabo? 'big digit', although some consultants include the thumb and the big toe when indicating hand and foot respectively. For all we know, most of the complex body part terms in Jahai may have such a spatial rather than 'part of' relation between their components. There is a couple of tempting exceptions though: the terms denoting palm/sole and back of hand/foot. These are easier thought of as parts, presumably because their contours so clearly coincide with those of their 'host' feature. Incidentally, it is interesting to note in this context that these terms involve the only documented cases of metaphorical extension from other parts of the body, e.g. 'hand-chest'. The productive constructions involving the distributed categories hair, skin, flesh and bone, e.g. sec gor, literally 'lower leg flesh', also represent probable 'parts' (although on the basis of their productivity they are not treated here as proper body part terms). In sum, like the simplex terms, complex body part terms in Jahai do not easily lend themselves to hierarchical arrangement.

On the basis of the linguistic aspects examined here, the Jahai system of anatomical terminology cannot be straightforwardly assigned a clear hierarchical structure. There are instead interesting indications that the lexicon sometimes avoids such a structure. If we still choose to describe it in hierarchical terms, it is clear that the resulting partonomic structure will exhibit only two or three levels: the first level is represented by ley 'body'; a fine-grained second level is made up of a wide range of parts directly possessed by body (represented by both simplex and complex terms); and a handful of simplex and complex terms (mainly associated with the hands and feet) may form a third level.

\section{Conclusion}

Jahai exhibits an extensive lexicon of terms referring to parts of the body. The main portion of this lexicon is represented by simplex terms, a smaller part consisting of complex terms. Simplex as well as complex terms pay attention to fine anatomical detail, but the system displays a conspicuous lack of labels for major parts like trunk, limb, arm and leg. Close examination of the extensional range of body part terms and how the relationship between them is expressed linguistically provides only little evidence of hierarchical 
structure of the lexicon, the Jahai system thus having difficulties adhering to the presumed universality of such hierarchy in the body part domain.

\section{Acknowledgements}

I wish to express my acknowledgements to the Economic Planning Unit, Putrajaya; the Department of Aboriginal Affairs, Kuala Lumpur; the Department of Speech and Hearing Sciences, National University of Malaysia, Kuala Lumpur; and the Jahai community of Sungai Banun, Hulu Perak. I have benefited from interesting discussions with Melissa Bowerman, Nick Enfield, Alice Gaby, Bill Hanks, Nicole Kruspe, Asifa Majid, Miriam van Staden, Angela Terrill and Claudia Wegener, and I am grateful to two anonymous reviewers of Language Sciences for helpful input. This research was carried out with the support of the Max Planck Society and a European Community Marie Curie Fellowship. The author is solely responsible for information communicated and the European Commission is not responsible for any views or results expressed.

\section{References}

Andersen, E.S., 1978. Lexical universals of body-part terminology. In: Greenberg, J.H. (Ed.), Universals of Human Language, Word Structure, vol. 3. Stanford University Press, Stanford, pp. 335-368.

Austin, P., 1992. A Dictionary of Thalanyji. Western Australia, La Trobe University.

Benjamin, G., 1976. Austroasiatic subgroupings and prehistory in the Malay Peninsula. In: Jenner, P.N., Thompson, L.C., Starosta, S. (Eds.), Austroasiatic Studies Part I. The University Press of Hawaii, Honolulu, pp. 37-128.

Blake, B.J., 1979. Pitta-Pitta. In: Blake, B.J., Dixon, R.M.W. (Eds.), Handbook of Australian Languages. John Benjamins B.V., Amsterdam, pp. 182-242.

Brown, C.H., 1976. General principles of human anatomical partonomy and speculations on the growth of partonomic nomenclature. American Ethnologist 3, 400-424.

Burenhult, N., 2002. A Grammar of Jahai. Unpublished Ph.D. dissertation, Lund University.

Coope, A.E., 1993. Malay-English English-Malay Dictionary. Hippocrene Books, Inc., New York.

Dixon, R.M.W., 1991. Words of Our Country: Stories, Place Names and Vocabulary in Yidiny, The Aboriginal Language of the Cairns-Yarrabah Region. University of Queensland Press.

Enfield, N.J., this volume. Elicitation guide on parts of the body. In: Majid, A., Enfield, N.J., van Staden, M. (Eds.), Parts of the Body: Cross-Linguistic Categorisation. Special Issue of Language Sciences, doi:10.1016/ j.langsci.2005.11.003.

Feneis, H., 1974. Anatomisches Bildwörterbuch. Georg Thieme Verlag, Stuttgart.

Gaby, A.R., this volume. The Thaayorre 'True Man': Lexicon of the human body in an Australian language. In: Majid, A., Enfield, N.J., van Staden, M. (Eds.), Parts of the Body: Cross-Linguistic Categorisation. Special Issue of Language Sciences, doi:10.1016/j.langsci.2005.11.006.

Kruspe, N., 1999. Semelai. Unpublished Ph.D. thesis, University of Melbourne.

Kruspe, N., 2004. A Grammar of Semelai. Cambridge University Press, Cambridge.

Meira, S., this volume. Tiriyó Body Part Terms. In: Majid, A., Enfield, N.J., van Staden, M. (Eds.), Parts of the Body: Cross-Linguistic Categorisation. Special Issue of Language Sciences, doi:10.1016/j.langsci.2005.11.009.

Osborne, C.R., 1974. The Tiwi Language. Australian Institute of Aboriginal Studies, Canberra.

Rischel, J., 1995. Minor Mlabri: A Hunter-Gatherer Language of Northern Indochina. Museum Tusculanum Press, Copenhagen.

van der Sluys, C.M.I., 1996. Why the Jahais view sharing as a 'passing-on of gifts'. Paper presented at The 7th International Conference on Hunting and Gathering Societies (CHAGS 7), 1993, Moscow. 
van der Sluys, C.M.I., 1999. The Jahai of Northern Peninsular Malaysia. In: Lee, R.B., Daly, R.D. (Eds.), The Cambridge Encyclopaedia of Hunter-Gatherers. Cambridge University Press, Cambridge, pp. 307-311.

van Staden, M., Majid, A., this volume. Body colouring task. In: Majid, A., Enfield, N.J., van Staden, M. (Eds.),

Parts of the Body: Cross-Linguistic Categorisation. Special Issue of Language Sciences, doi:10.1016/ j.langsci.2005.11.004.

Wilkins, D.P., 1981. Towards a Theory of Semantic Change. Unpublished Ph.D. thesis, Australian National University, Department of Linguistics. 